\section{Apolipoprotein C-II}

K. J. Lackner ${ }^{1}$ und D. Peetz ${ }^{2}$

${ }^{1}$ Institut für Klinische Chemie und Laboratoriumsmedizin, Universitätsmedizin Mainz, Mainz, Deutschland

${ }^{2}$ Institut für Labormedizin, Helios Klinikum Berlin-Buch, Berlin, Deutschland

$\operatorname{Synonym(e)~ApoC-II~}$

Englischer Begriff apolipoprotein C-II

Definition ApoC-II ist ein Apolipoprotein der triglyzeridreichen L Lipoproteine und High Density Lipoproteine (s. - High Density Lipoprotein).

Molmasse $8,9 \mathrm{kDa}$.

Synthese - Verteilung - Abbau - Elimination ApoC-II wird als 101 Aminosäuren langes Proprotein in der Leber synthetisiert. Im Plasma überwiegend an VLDL und HDL gebunden.
Funktion - Pathophysiologie ApoC-II ist ein obligater Kofaktor der $\gg$ Lipoproteinlipase. Genetische Defekte führen zur autosomal rezessiv vererbten familiären Chylomikronämie und sind phänotypisch nicht von Lipoproteinlipasedefekten zu unterscheiden. ApoC-II aktiviert die LCAT.

Bei Chylomikronämien wird ApoC-II im Rahmen der Lipoproteinlipaseanalytik in einer Stufendiagnostik mit untersucht.

Untersuchungsmaterial - Entnahmebedingungen $>$ Lipoproteinlipase.

Analytik > Isoelektrische Fokussierung, 2D-Gelelektrophorese (s. $\triangleright$ Gelelektrophorese), DNA-Sequenzierung.

Indikation Bei V. a. familiäre Chylomikronämie und Ausschluss eines Lipoproteinlipasedefekts kann ein ApoC-IIDefekt durch die o. g. Methoden gesichert werden.

\section{Literatur}

Schwandt P, Parhofer KG (2007) Handbuch der Fettstoffwechselstörungen, 3. Aufl. Schattauer Verlag, Stuttgart, S 156-185 